\title{
Epistemological agency: a necessary action-in-context perspective on new employee workplace learning.
}

\author{
Ray Smith \\ Griffith University, Australia
}

\begin{abstract}
This paper discusses research premised on the view that new employees' necessary learning actions may be said to constitute a sociocultural constructivist epistemology of necessity. It examines the work and learning activities of three new employees during their first months at a wholesale fruit and vegetable company. It proposes that what new employees must 'do', is engage in a range of working and learning activities, epistemic actions, that may be conceptualised as their exercising epistemological agency. That is, they are necessarily engaged in the practice of personally managing the diversity of factors that mediate their construction of knowledge. In doing so, they control the social suggestion of their workplace within their need to learn what is necessary for work. The paper further suggests these mediating factors constitute a workplace learning agenda that comprises the priorities of the new employees' actions at work. This agenda is identified across five interrelated action sets. These sets emerge from data analysis as major mediators of the new employees' learning. Additionally, it suggests that change in this agenda may indicate what learning is being undertaken and how the development of workplace intersubjectivities or shared understandings, may subsequently occur. These suggestions place new emphasis on the individual in determining their contribution to the social nature of learning. They begin to more fully account for the personal purpose and consequence of learning at work.
\end{abstract}

\section{Necessity and workplace learning}

The sociocultural constructivist theories of learning and development (e.g., Vygotsky 1978, Leontev 1981, Rogoff 1990, Wertsch 1998) that are the conceptual basis of the research this paper presents, attribute the individual with the role of constructor of their own knowledge. This role is necessarily active - the individual is more than a passive recipient of knowledge that is external to them. Individuals are therefore actively engaged in the process of their selfdevelopment as they construct the knowledge that makes sense of and gives meaning to their experience (Valsiner 1998). This experience is situated in contexts that are socially organised and historically embedded and, therefore, afford the individual opportunity to participate in the cultural practices that define their particular context (Lave 1993). Many would assert that it is by such participation that the self is identified and positioned in social reality (eg, Giddens 1991, Fenwick 1998, Pusey, 2003). Through this participation the individual may be construed as a learner who enters into interactive relationships with the people, products and processes that constitute the cultural practices of their context. Learning and development is based in this interaction (Rogoff 1990, Valsiner 1994, Wertsch 1998) and is variably understood and described by different theorists who have examined these concepts in the social and cultural contexts of work. For example, Lave and Wenger (1991) reference it as situational, being based in graduated levels of participation in communities of practice. Wertsch (1995) theorises it as mediational, being based in the interplay of a unique 
combination of personal and contextual moments that constitute the major influences on action. Billett (2004) describes it as relational, being based in the interactions of individual ontogeny and the affordances and constraints of the particular workplace. Bailey, Hughes and Moore (2004) present it as experiential, being based in access to and acceptance of the social means of knowledge control to which the individual is subjected. Rogoff (1995) defines it as appropriation when individuals, through their involvement in one cultural activity, are in the process (conscious or otherwise) of becoming prepared for subsequent involvement in related activities. This paper is likewise concerned with the nature of the interaction between the individual worker and the cultural practices that constitute their workplace. It presents research that accounts for learning in the workplace as the active, iterative and transformative experience of three participant new employees who exercise their personal agency as a 'livedout' dialectical engagement with the necessities of their circumstance. Its primary focus is on learning that may initially be described as instrumental within the limits of these new employees' induction into the practices and requirements of their work. This instrumentality, however, evidences more than the pragmatics of learning to comply with the procedural requirements of work activities and the cultural systems in which they are embedded. It evidences the operation of individuals' personal epistemology, the unique deployment and development of conceptions of knowledge and learning that support and mark new adult employee experience (Hofer 2002, Bauer et al 2004). Particularly, this instrumentality evidences the bases on which individuals act upon and utilise their ways of knowing and understanding the necessities and demands of new work and its associated learning. That is, workplace learning, what is learned and how it is learned, and the subsequent performance success it may or may not generate for its participants, is the conditional outcome of the personally purposeful and intentional interaction between the three new employees with their unique personal epistemologies and the necessities that define their immediate engagement in the workplace.

The necessary learning actions, or epistemic actions, new employees must undertake to meet the performance requirements of their new job may be seen to constitute a constructivist epistemology of necessity. This necessity can be said to manifest in two fundamental ways. Firstly, learning can be viewed as a necessity of the demands of its context (Lave 1993). That is, the inescapable press of society's discourse (Archer 2000), through its operant cultural practices, makes learning an inevitable consequence of circumstances requiring work. Workplaces are not venues of inactivity. They are sites of goal-orientated activities that make demands of their participants. New employee learning is, therefore, necessitated by the contextual requirement of work. The implicit nature of this necessity may sometimes be easily overlooked (Noon \& Blyton 1997) when learning practices as such become indistinguishable from the productive work practices that are the usual performance requirements of a new job (Billett 2001b). For example, learning is apparent when a new employee preparing a delivery order locates an unfamiliar product in its designated storage area for the 'first' time. Such learning may seem far less apparent, if no less salient, second, third and tenth time despite its iterative qualities (Harris et al 1998) and the opportunities these represent for contending with the subtle variations that characterize even the most repetitive of actions (Napier \& Gershenfeld 1999). New employee learning therefore can be said to be a contextual necessity. In any workplace, the new employee must do something. Doing something is the learning (Rogoff \& Lave, 1984) that the workplace necessitates.

Secondly, learning can be viewed as a necessity of individual agency, that is, as the indispensable personal involvement in the activities of the workplace. The personal choices and decisions that the new employee makes at work constitute their learning to participate. 
Learners are selective, discriminating and therefore regulative of their actions as they evaluate and choose from the wealth of information contained in their situation (Valsiner 1998). This, together with the equally personal thoughts and actions that underlie the exercise of this agency, represents the unavoidable learning that is the new employee's personal response to the requirements of the workplace. In this sense, learning is a necessity of the new employee's condition. Their need of it in part defines them as new. It is what the new employee doesn't know, what workplace requirements they are unfamiliar with, what essential workplace practices they are unable to perform in order to meet the demands of their job, that become the parameters of their learning necessity. Involving themselves in this learning necessitates their personal agency. As such, new employees are always agentic, always exercising their agency, always agents of their engagement as they negotiate the necessities of not only what they learn, but how, when and why they learn. The ability to contend with this necessity of learning may be viewed as a personal predicament, a selfdefining circumstance through which the efforts and capacities for learning will be utilised and tested (Giddens 1991). The indispensable thoughts and actions that constitute this personal experience define it as learning necessity - "If we are thinking and acting, we are learning” (Billett 2001b:6). Such a personal and holistic understanding of agency is similarly advanced by Archer (2000: 314) who maintains that "the agent is literally the parent of the actor". Personal agency then, is here more broadly viewed than the discretionary power or capacity to influence and or change existent work practices. It is the personal qualification of action, the evaluative practice (Archer 2000) that conditions the focus and intensity of personal engagement in the immediate necessities of learning. It involves desire, prioritising cares and concerns and integrating such personal elements with the goals and practices of the workplace. Agency as such, positions the individual worker as the locus of cultural action that animates and activates the knowledge on which such practice is based. This knowledge is both socially sourced and personally experienced by the necessity of engagement. New employee learning therefore can be said to be a personal necessity that is obviated by the thoughts and actions that will accompany the experience of their need to know what is required of them. It becomes a necessity of the exercise of their personal agency in making the choices and decisions their learning needs demand.

Workplace learning has personal purpose and consequence that must be accounted for by constructivist theories that seek to represent it as a conflation of social and individual agency. Failure to do so can have the unwarranted consequence of viewing learning solely as an enculturation process that invites, if not forces, individuals to engage in the social press of their circumstance. In this way, the social suggestion of the workplace may come to be seen as pre-eminent in considerations of the nature of learning that takes place there. This may be particularly evident when learners are new employees and subject to a host of the new and unfamiliar. This tendency may seem to negate or camouflage the agency of the individual to determine the nature of their engagement in the cultural practices that are their immediate experience at work. It is proposed here, that conceptualising learning as responsive to an epistemology of necessity, that captures the relative import of individual and social agency as outlined above, provides a conceptual basis by which the personal purpose of learning and the intentionality of the learner's actions can be accounted. Further, it suggests that the individual new employee-learner is best understood in their active role as the agent who, through the necessity of their situation, exercises their agency in the personal construction of the knowledge necessary for their participation in the activities of the workplace. This agency is here conceptualised as epistemological agency. It is posited as a concept that encapsulates the necessary actions and purposeful intentionality of the new employee-learner as they undertake the personal management of the actions and interactions that comprise their 
individual construction of knowledge for and through work. It combines the process of engagement in the contextual work and learning activities that are necessitated by the workplace, that is the actions that evidence agency, with the product or knowledge that is the epistemic legacy of such agentic actions. These are epistemological concerns that emerge from person-dependent psychological considerations of knowledge-in-use, be it tacit or explicit, propositional or procedural, and/or experientially new or routine and familiar. So, epistemological agency is offered here as a potentially useful term to carry a fuller understanding of what personally initiates and directs individuals' learning as they exercise their independence through participation in such cultural activities as work. It captures learning and working as synonymous yet differently analytically qualified activities that unite individuals and their contexts through the necessity of personal action. Learning, like working, is the active process and product of epistemological agency. The term recognizes knowledge as practiced through cultural activity (Leontev 1981) that is personally utilized (Schommer 1998) for private purposes of care and concern (Frankfurt 1988) beyond the conditions and sensorship of personal beliefs (Bauer et al 2004) and within the influence of but not the determination of socio-cultural context (Archer 2000). It therefore privileges the new employee-learner with an autonomy that accounts for individual difference through ontogeny and utility and rightfully focuses learning on the actions of the learner, on their necessary actions-in-context.

\section{Exploring epistemological agency in the workplace}

The research took place over a six-month period at FruitCo, a well-established wholesale fruit and vegetable business operating in the central markets precinct of an Australian capital city. FruitCo was selected as the site for the project because of its high staff turnover and the absence of a need of any formal qualifications to secure work as an order packer. The volunteer new employee participants, Michael, Chris and Alice, were the three of ten new employees who started work at FruitCo and had not left or been sacked at the end of the research period. They had worked, five, three and two months respectively. Michael, in his early twenties, was a salesman/buyer with a passion for fast cars and had come from work in a fast food chain. Chris, in his late teens, was a storeman/packer who had picked fruit and worked for a demolition company. Alice, a packer and in her early forties, was married with teenage children and had worked many part time jobs. They were initially employed to prepare and pack fresh produce for delivery and had no specific experience of the work prior to coming to FruitCo. For each of them, the work represented unique and welcome opportunities. Michael was pursuing a career in sales and eager to learn and advance. Chris was appreciative of the work as the seasonal nature of his previous work had forced his unemployment. Alice enjoyed the flexibility the early starts afforded her and the extra income it generated for the family.

The procedures adopted comprised the researcher working alongside the participants as a fellow new employee positioned as an 'active-member-researcher' (Adler \& Adler, 1994). This established the researcher as an insider with a genuine situational identity engaged in the collaborative social interaction of interpretive ethnographic data (Angrosino \& Mays de Perez 2003). The researcher had previous experience of working with fresh produce in circumstances similar to those of FruitCo and was therefore familiar with fruit and vegetables and their handling. In all other respects, that is, familiarity with FruitCo's specific staff and practices, the researcher was a new employee colleague of the three participants and subject to the same conditions of employment. Extensive workplace observations together with numerous semi-structured interviews and verification sessions with Michael, Chris and Alice, generated a wealth of data that presented the research as an interpretive practice of both the 
researcher and the new employee participants. The focus of this interpretive practice was the new working and learning activities of the three participants. The insider status of the researcher was fundamental in establishing a firm understanding of FruitCo's new employee staff expectations and operating procedures, and importantly, an open rapport with the three participants that encouraged their willingness to discuss their immediate experience. The researcher worked to ensure, insofar as this is possible, that researcher experience was not accommodated through the related accounts of the three participants. Together, they sought to map and understand only the volition and mediations of the working and learning experiences of the three new employees through two guiding questions.

1. What constitutes the epistemological agency of the new employee, and,

2. How and on what basis it might be enacted in the initial stages of their employment?

\section{Learning mediations in the workplace}

From a thematic analysis of the interview and observation data, five interrelated categories or sets of action mediations emerged as the dominant factors influencing the three new employees' work and learning practices. They emerge from the data, not as analytic contructs that gather the experiences of the three participants, but as parameters of priority that capture those aspects of Michael, Chris and Alices' actions they verify to be essential to their working and learning necessities as new employees. Each action set captures a relatively discrete group of "dialectically interacting moments" (Wertsch 1995: 60). These moments, or aspects of action, bring together the personal and contextual necessities of the individual new employee's workplace experience. They comprise the intentional and purposeful, accidental and even ill conceived evaluations and decisions that are the foundations of personal agency (McCann 1998) in tandem with the contextual factors that invoke them. Such a collection could be said to constitute an inventory of the participant new employees' self-perceived reagents that enable their learning to proceed. Taken together, these inter-related action sets may be seen to comprise the necessary actions that mediate and are mediated by Michael, Chris and Alices' workplace learning.

The five action sets, briefly outlined and illustrated below, are;

1. Time.

2. The Organisation.

3. Motivation.

4. Learning strategies.

5. Identity.

Time - convokes influences of its personal perception, workplace imposition and subsequent utilization and management in the need to secure successful workplace performance. All three of the new employees demonstrate an evaluative awareness of their work tasks in relation to the duration, arrangement and utilisation (Noon \& Blyton 1997) of time taken (personal perception) and time required (contextual imposition) to successfully complete their tasks. As such, time is both an objective commodity and a subjective experience. As a commodity that workers trade for benefits, time is both an imposition of the job and a resource to be controlled. It is necessarily accepted, managed and deployed by each of the new employees in ways that reflect its utility for them. For example, the constant pressure of shouting bosses, delivery deadlines and the frustrating foot tapping of impatient customers meant for Chris - when you rush, like all the time, you can't take the time to find out what you're doing wrong even though you know you must be doing something wrong. The frenetic pace of the workplace both demands and hinders Chris' learning. He manages this timeinduced propensity for error by literally stopping - you've got to stop every now and again 
just so you can think about what you're doing. This reflection and review time is a necessary component of the time both taken and required to complete his tasks. Making mistakes and managing time are contextual and personal necessities that engage Chris in the exercise of his epistemological agency. For instance, he learned that the boss reprimanding him for 'getting it wrong again' presented an opportunity to stop and reflect - While he was going off at me about something that happened ages ago, I'd be thinking about what I was doing now and how to get that right.

These brief illustrations of Chris' new employee experience, reveal time as a highly influential and complex mediator of learning - this seems especially true for FruitCo staff who start work at 2.00am and work constantly on their feet for 8-10 hours without a break. Time can be seen as much a function of agency as agency is of time. Epistemological agency, therefore, may be understood in part as a managed manipulation of the personal and contextual time necessary to learning.

The organisation - concerns issues of the workplace culture. FruitCo constitutes a learning context of contradiction and dilemma, a contested terrain into which new employees are simultaneously invited to participate and expected to perform (Billett 2001a). Its cultural practices and artefacts, skill requirements and assorted personalities represent an array of knowledge bases new employees will necessarily engage with in the course of their work. For example, knowledge of product quality policies, customer expectations and the dispositions of colleagues represent necessary information new employees need for successful workplace performance. Because the initial sources of this information are held in the workplace, accessing them requires the fostering and maintenance of numerous inter-personal relationships. The personal communications management this demands equates with new employees' matching necessary information for the specific situation with the appropriately knowledgeable co-worker. That is, quickly finding out who knows what and how to relate to them is the exercise of epistemological agency across personal and contextual necessities of workplace relationships. For Alice, this meant the more experienced Marg - Marg is the one that I immediately go to for anything because she's the first person that I was actually teamed with to show me the basics of picking out the orders, picking out the right stock for the right customer. However, the meaning of 'teamwork' was very differently interpreted by the two women. Alice learned immediately, she was on her own - Marg said there's no point helping her. I might as well start doing an order and if I have any problems, come and see her. Asking questions of Marg was not as easy as it seemed. Her own work commitments often meant she was unavailable and this necessitated seeking assistance from other staff. In realising her need of information from other staff Alice effectively became manager of the relationships that met her information needs. Poor management meant bad information that equated with wasted time and the risk of error and its uncomfortable consequences with either a disgruntled customer or the boss or both - You don't ask Louis about the mushrooms. Oh he'll tell you they're fine or the right size or whatever but he won't really know. I found out the hard way about Louis.

The management of information and access to it are aspects of new employees' epistemological agency. At FruitCo these are relationship issues that involve the communication systems and processes that guide participation (Rogoff 1995). New employees must engage in these practices and establish some control or management of them. In accepting this responsibility and acting on it, new employees exercise their epistemological agency. This is evidenced through their management of these fundamental relationships that are important organisational factors mediating their work and learning. 
Motivation - considers the necessity and goals of learning. Conceptually, motivation is concerned with why people do what they do. It seeks to offer understanding of, even explanation for, people's actions. It is perhaps best understood as a product and evidence of agency rather than a foundation for the satisfaction of personal psychological needs. Much of what individuals 'do' is not responsive to motivation but rather undertaken as the routine necessities of their circumstance (Giddens 1991). For Michael, the motivation to work is driven by the opportunity to do so - I enjoy the work. Every aspect of it is to me interesting and I'm here because I want to be. I know what I'm doing if you know what I mean. There is no need to distinguish between his reasons for action and what motivates them because he explains his intentions through his actions, that is, what Michael is doing is why he is doing it. Therefore, it is not what motivates, or how much motivation an individual has, but rather the actions enabled by participation in culturally meaningful activities that promote and engage the individual's motivation. Michael is motivated to work. Likewise he is motivated to learn. His exercise of epistemological agency evidences this motivation to learn as responsive to the personal and contextual necessities of his work. When I'm ordering the stock (sprouts) I just look at the shelves and I know if I order too much of it we don't sell it so I order only a little bit of each thing, but if we sell it the next day then I've got to turn around and organise some more. Michael is motivated to find the balance between stock order and purchases because this is necessitated by the decision requirements of his job. Getting it right means working efficiently which means learning well. For Michael, as for the other new employees, the action of making decisions and choices is the exercise of epistemological agency. He can be construed as either more or less motivated or intrinsically or extrinsically motivated to make these decisions but such qualities offer only a taxonomy of descriptive qualifiers of his actions. These are the mediational moments (Wertsch 1998) that personalize and contextualise his motivation as both responsive to and productive of the actions necessary to his workplace participation.

Learning strategies - acknowledges prior learning, current experience and its deployment. Learning to work and learning to learn skills and strategies are practices that are both brought to the job as previous experience and developed on the job as situated learning (Harris et al 1998). These learning strategies, as actively utilised and developed by the three new employees attest to the purposeful nature of their learning in the workplace. Their deployment evidences the exercise of epistemological agency as responsive to and productive of active workplace participation. Practices such as questioning, listening, watching and experimenting were constant initiators of the evaluations and judgements that predicated that actions of the new employees. For Michael, questioning was almost a conversational practice. He asked questions constantly as a means of gathering the information he required and as a means of building rapport with other staff and customers. For him, the whole workplace was a zone of proximal development (Vygotsky 1978) and everyone in it a guide to be utilised in his pursuit of workplace knowledge - You ask questions. If you're not sure about it you go and ask someone who you think will be sure and if they're not sure about it you ask someone else. Alice was attuned to the conversations going on around her - Keep your ears open to what was being said around you helps. For her, such attentive listening to co-workers could enable the gleaning of information about stock availability or location that could reduce the need of questioning at a later stage. Chris was younger and less confident about seeking information from his co-workers - I like figuring things out for myself. Basically you could go in and you're thinking OK I need to get something and its either this one or this one and you know everyone else is just too busy to help you so you just guess and grab something. You'll find out later if it's the right thing or not. This created problems for him early in his employment 
as his calculated guesses were often wrong and orders he packed were returned with customer complaints.

FruitCo requires its new employees to be successful self-directed learners from the outset. Its minimal provision of guided support together with grueling conditions, that importantly include the constant threat of sacking should the boss feel so inclined (each of the new employees had witnessed the arguing and emotions of an on-the-spot dismissal), demands of its new employees, immediate and successful exercise of epistemological agency. In doing so, Michael, Chris and Alice take control of the personal and contextual learning necessities that define them as new employees.

Identity - captures issues of the self, its roles, responsibilities and capacities to meet the demands of its situation. Within Identity, the 'who' that is exercising their epistemological agency can be seen as a complex set of identities (Ryan \& Deci 2003) that constitute the self. Managing the self-in-action requires the capacity and willingness to adopt workplace identities that reflect the necessary group affiliations the new employees establish. So, the private and independent individual becomes a co-worker, a staff team member, who in turn becomes a company representative. These different performance roles must be self-regulated and controlled (Baumeister 2001), that is managed and developed. The new employees learn how to be team members and what is required of company representatives. As they manage this learning, their agendas, that is, the mediations that constitute their actions, grow and subsume the new reasons and purposes of engagement in workplace activities that attach to their variously operant identities. For example, Alice negotiates her boss's acceptance of a condition of her employment that she be able to go home during the morning and get her daughter off to work and then return to complete her hours. This is the 'me' identity of the self at work, the private and independent Alice who appreciates the freedom her negotiations afford her to prioritise her family concerns. However, as Alice begins to identify herself as a staff team member, she realises how her personal priorities impact negatively on the team's efforts. Her absence means more work for the rest of the team. She acknowledges this on those days when she does not have to attend to her daughter and is able to contribute fully to the team workload. She recognises and enjoys the team's achievements and her new selfidentity as a team member, the 'we' who is necessitated by her work - today we must have worked well as a team because we actually got the very last order out before 9.30. and its usually around the 10.30 to 11.30 mark before it normally gets out. So that wasn't just me, that was a group effort. Additionally and simultaneously, the 'us' identity is developing through a growing awareness of the mediations outside the workplace that directly impact her exercise of epistemological agency. These include the external forces of customers and suppliers who are never-the-less integral aspects of the workplace culture. Alice recounts - I did pack the right things but somewhere between me packing it and the customer getting it, they got the wrong thing ... we could have lost the business. The 'we' here is the 'we-thecompany' that is the foundational 'us' identity of the self in action at work. This identity of the self does not arrive at the workplace as a new employee ready to start work. Rather, and like the 'we' the team member, it could be said to arrive as a potential, a capacity of the self that has already been ontogenetically constituted as an inclusively separate subject (Valsiner 1994). It develops through the new employee's on-going participation in the practices of the workplace.

These operant workplace identities enable a view of the self at work that is multiply constituted by a plasticity of established and emerging identities. These identities meet the personal and contextual necessities of the workplace through the new employees' exercise of 
epistemological agency. Further, these identities establish the self, in part, as a present and emerging initiator and product of epistemological agency.

\section{Defining epistemological agency}

Together, the five action sets affirm an understanding of epistemological agency as the new employees' construction of knowledge in the workplace across a broad range of personal and contextual mediations. What Michael, Chris and Alice demonstrate, and the action sets document, is a capacity to control and direct the nature of their learning at work. This capacity, it is proposed here, is the on-going and developmental management of the personal and contextual necessities that characterize their experience as new employees. That is, Michael, Chris and Alice take charge of the conduct and accomplishments of their actions at work. They manage their learning by managing themselves and their contexts through the mediations that are their actions at work.

What they manage, that is the mediations revealed through the five inter-related action sets, can be said to constitute their respective workplace learning agendas. Their agendas are more than the work requirements of their jobs. Their agendas are the actions undertaken to secure the exercise of their epistemological agency, the manifest of the "dialectically interacting moments" (Wertsch 1995:60) that is their new employee experience. Through their time and growing experience at FruitCo, their respective workplace-learning agendas can be seen to expand and reprioritise in directions that are consistent with and observable through the different action sets. This movement in agenda can be seen to reveal a directionality of learning that may be mapped across the action sets. For example, Chris, who initially did not know all the products listed on the packing sheet and would simply choose what ever was at hand in the hope that his error would later be pointed out to him, comes to understand this experimental trial and error approach to product selection as inappropriate. He alters his learning strategies to reflect this necessary change in his workplace-learning agenda and persists with his questioning of the other staff. Had he not done so soon enough, it is reasonable to assume he would have been sacked. From this directionality of learning, arise two key issues that impact sociocultural constructivist learning theories. The first concerns questions about what kinds of knowledge will be constructed. The second concerns how these knowledge constructions relate to the development of the intersubjectivities that are the shared understandings of the workplace.

Firstly, actions that expand the individual's agenda in ways commensurate with their management capacities will characterise their initial engagement in their new job. These are the actions of the independent self-identity, the 'me' who arrives at work with established ways of knowing, an established personal epistemology that meets the new workplace necessities. The action sets don't operate to predict what specific knowledge will be constructed from such a foundation, but rather to indicate how the individual's agenda may expand relative to this foundation. Chris's agenda change noted above evidences this. Epistemological agency can thus be seen to have learning directional qualities that are evidenced through movements in new employees' workplace learning agenda. These movements are the knowledge in use (Lave 1993) that is sociocultural knowledge construction (Rogoff 1990).

Similarly, the learning directional qualities of epistemological agency may be indicative of learner resistance and incapacities. Michael, Chris and Alice not only learn to solve the problems their work presents, they also decide what problems are worth solving (Goodnow 
1990), in whose interests, and how much effort they will expend in solving them (Harris et al 1998). Movements in their workplace learning agenda reflect such management decisions. For example, Alice's learned mistrust of the more experienced Louis is a clear example. The numerous and valid reasons that support this choice of action temporarily deny her access to a rich information source that potentially affords increased learning support. Equally, this choice of action temporarily removes the perceived threat of unreliable information. Her management of this particular relationship, revealed primarily through the organisation action set, supports an agenda that initially reflects resistance to expansion within this area of the set. In this way, epistemological agency has learning directional qualities that may be interpreted as indicative of resistance to learning, inappropriate learning or failure to learn.

Secondly, epistemological agency involves the negotiation and shared acceptance of workplace meanings and understandings that create the congruence between new employees and the workplace. The action sets enable an analysis of the personal and contextual moments or mediations that comprise this congruence as the co-construction (Valsiner 1994) of knowledge through the exercise of epistemological agency. These moments can be read as the items on the individual new employee's agenda. As noted above, movement in the agenda evidences the learning that accomplishes knowledge construction. As knowledge is coconstructed, expansion of the agenda may correspond to a growing congruence between the new employee and their workplace. When this expansion is interpreted and evaluated similarly by the new employee and say their colleagues or bosses, or against the cultural norms that operate within the workplace, intersubjectivities, that is, shared understandings, may be seen to develop.

Epistemological agency then, becomes a conception of new employees' learning and working practice that is based in their necessary actions-in-context. It presents a way of unifying the personal and contextual influences of learning in the actions of the learner who is constantly negotiating their participation in the cultural practices of the workplace through their management of the mediations that characterise it. These mediations comprise a workplace learning agenda that can be mapped across a series of action sets that serve to profile and qualify the personal and contextual priorities operant as cultural necessities in the new employees' experience. Succinctly stated, epistemological agency is the personal management of the individual new employee's workplace learning agenda (Smith 2005). Conceptually, this view of workplace learning begins to more fully account for the personal purpose and consequence of learning within the sociocultural constructivist examination of the social origins of knowledge.

\section{References}

Adler, P.A. \& Adler, P. (1994) Observational techniques. In Denzin, N.K. \& Lincoln, Y.S. (Eds) Handbook of Qualitative Research. Thousand Oaks, California: Sage Publications. pp377392.

Angrosino, M. \& Mays de Perez, K. (2003) Rethinking observation: From method to context. In Denzin, N.K. \& Lincoln, Y.S. (Eds) Collecting and interpreting qualitative materials. $\left(2^{\text {nd }}\right.$ Ed.) Thousand Oaks, California: Sage Publications. pp107-154.

Archer, M. S. (2000) Being Human: the problem of agency. Cambridge: Cambridge University Press.

Bailey, T., Hughes, K. \& Moore, D. (2004) Working Knowledge: Work based learning and education reform. New York: RoutledgeFalmer.

Bauer, J., Festner, D., Gruber, H., Harteis, C., \& Heid, H. (2004). The effects of epistemological beliefs on workplace learning. Journal of Workplace Learning, 16(5), 284-292. 
Baumeister, R.F. (2001) Ego depletion and self control failure: An energy model of the self's executive function. Self and Identity. 1 pp129-136.

Billett, S. (2001a) Co-participation at work: Affordance and engagement. In Fenwick, T. (Ed) Sociocultural perspectives on learning through work. San Francisco: Josey Bass/Wiley.

Billett, S. (2001b) Learning in the workplace: Strategies for effective practice. Allen \& Unwin: Crows Nest NSW.

Billett, S. (2004). Co-participation at work: Learning through work and throughout working lives. Studies in the Education of Adults, 36(2), 190-205.

Fenwick, T. (1998). Women's Development of Self in the Workplace. International Journal of Lifelong Learning, 17(3), 199-217.

Giddens, A. (1991). Modernity and self-identity : Self and Society in the Late Modern Age. Stanford: Stanford University Press.

Goodnow, J.J. (1990) The socialisation of cognition: what's involved? In, Stigler, J., Shweder, R. \& Herdt, G. (Eds) Cultural Psychology. Cambridge University Press: Cambridge. pp259-286.

Harris, R., Willis, P., Simons, M. \& Underwood, F. (1998) Learning the job: Juggling the messages in on- and off-the-job training. (for the Australian National Training Authority) Leabrook SA: National Centre for Vocational Education Research.

Hofer, B.K. (2002) Personal epistemology as a psychological and educational construct: An introduction. In Hofer, B.K. \& Pintrich, P. (Eds) Personal epistemology: the psychology of beliefs about knowledge and knowing. Mahwah NJ: Lawrence Erlbaum Associates. pp 3-14.

Lave, J. (1993) The practice of learning. In Chaiklin, S. \& Lave, J. (Eds) Understanding practice: Perspectives on activity and context. Cambridge: Cambridge University Press. pp3-34.

Lave, J., \& Wenger, E. (1991) Situated Learning: Legitimate peripheral participation. Cambridge: Cambridge University Press.

Leontev, A.N. (1981) The problem of activity in psychology. In Wertsch, J.V. (Ed) The concept of activity in Soviet psychology. New York: Sharpe. pp37-71.

McCann, H. J. (1998) The works of agency: On human action, will and freedom. Ithaca: Cornell University Press.

Napier, R.W. \& Gershenfeld, M.K. (1999) Groups: Theory and experience. Boston: Houghton Mifflin.

Noon, M. \& Blyton, P. (1997) The realities of work. London: Macmillan Business.

Pusey, M. (2003). The Experience of Middle Australia. Cambridge, UK: Cambridge University Press.

Rogoff, B. (1990) Apprenticeship in thinking: Cognitive development in social context. New York: Oxford University Press.

Rogoff, B. (1995) Observing sociocultural activity on three planes: participatory appropriation, guided participation and apprenticeship. In Wertsch, J.V., del Rio, P. \& Alvarez, A. Sociocultural Studies of Mind. New York: Cambridge University Press. pp139-164.

Rogoff, B. \& Lave, J. (1984) (Eds) Everyday cognition: Its development in social context. Cambridge: Harvard University Press.

Ryan, R. \& Deci, E. (2003) On assimilating identities to the self: A self-determination theory perspective on internalisation and integrity within cultures. In Learry, M.R. \& Tangney, J.P. (Eds) Handbook of self and identity. New York: Guildford Press. pp253-271.

Schommer, M. (1998) The role of adults' beliefs about knowledge and learning in school, work and everyday life. In Smith, M.C. \& Pourchot, T. (Eds) Adult Learning and Development: Perspectives from Educational Psychology. Hillside, NJ: Erlbaum. pp127-143.

Smith, R. (2005) Epistemological agency and the new employee. Australian Journal of Adult Learning, 45 (1)

Valsiner, J. (1994) Bi-directional cultural transmission and constructive sociogenesis. In de Graaf, W. \& Maier, R. (Eds) Sociogenesis re-examined. New York:Springer.

Valsiner, J (1998) The guided mind: A sociogenetic approach to personality. Cambridge: Harvard University Press.

Vygotsky, L.S. (1978) Mind in Society: The development of higher psychological processes. Cambridge: Harvard University Press. 
Wertsch, J.V. (1995) The need for action in sociocultural research. In Wertsch, J.V., del Rio, P. \& Alvarez, A. (Eds) Sociocultural Studies of Mind. New York: Cambridge University Press. pp56-74

Wertsch, J.V. (1998) Mind as Action. New York: Oxford University Press.

This paper was presented at the 4th International Conference on Researching Work and Learning, Sydney 2005.

This paper was published:

Smith, R. (2006) Epistemological Agency: a necessary action-in-context perspective on new employee workplace learning. Studies in Continuing Education 28(3), 291-304. 